\title{
Sex Differences In The Mortality Of Hospitalized Patients With COVID-19 And Non-ICU Policies In The Netherlands
}

\section{Astrid Freytag}

Radboud University Medical Center

Jacobien Hoogerwerf

Radboud University Medical Center

Anton S.M. Dofferhoff

Canisius-Wilhelmina Hospital

Nico Janssen

Radboud University Medical Center

\section{Marc Blaauw}

Radboud University Medical Center

Robert-Jan Hassing

Rijnstate Hospital

\section{Marjan van Apeldoorn}

Jeroen Bosch Hospital

Angèle Kerckhoffs

Jeroen Bosch Hospital

Karin Veerman

St. Maartenskliniek

Josephine van de Maat

Radboud University Medical Center

Sabine Oertelt-Prigione ( $\nabla$ sabine.oertelt-prigione@uni-bielefeld.de)

University of Bielefeld https://orcid.org/0000-0003-3856-3864

\section{Research}

Keywords:

Posted Date: February 15th, 2022

DOI: https://doi.org/10.21203/rs.3.rs-1325353/v1 
License: (c) (i) This work is licensed under a Creative Commons Attribution 4.0 International License. Read Full License 


\section{Abstract}

Introduction: Several international studies have reported sex differences in COVID-19 mortality. The Dutch healthcare system is characterized by as strong focus on primary care and active patient participation in medical choices, such as invasive therapies. This study aims at identifying potential sex-specific predictors of in-hospital mortality and non-ICU policy in patients with COVID-19.

Methods: In this observational cohort study, we included participants hospitalized with COVID-19 during the first wave (March-May 2020) of the pandemic in six regional hospitals in the Netherlands. We computed descriptive statistics and logistic regression models using sex-disaggregated data to identify predictors of in-hospital mortality. Followingly, we analyzed the clinical features of female and male COVID-19 patients who had a non-ICU policy.

Results: We included 1262 patients (63.7\% men) in this study. Higher age, higher LDH level, lower diastolic blood pressure, and lower peripheral oxygen saturation were associated with in-hospital mortality in female and male patients. Shorter symptom duration before admission and more comorbidities associated with in-hospital mortality only in female patients. $33.8 \%$ of the female and $30.6 \%$ of the male patients had a non-ICU policy. We identified a significant rise in this policy in female patients over the course of the first wave compared to males, which could not be explained solely by age and clinical differences.

Discussion: Potential sex differences in symptom development and the sex-specific impact of immune dysfunction on COVID-19 prognosis need further evaluation. Sex differences in ICU care preferences of these patients should be examined to identify underlying gender-related patterns.

\section{Introduction}

In late 2019 the first cases of Corona-Virus Disease (COVID-19) were identified in Wuhan province, China. In January 2020 the WHO declared the global pandemic, that currently exceeds 270 million cases and 5.3 million deaths worldwide (1). At the end of February 2020, the first person infected with SARS-CoV-2 was identified in the Netherlands leading to 3 million cases and 20.504 deaths at the moment of writing (2).

Since the beginning of the pandemic sex differences in COVID-19 mortality were reported (3) as well as the impact of gendered factors on healthcare access, care and social domains (4). Researchers stressed the need to focus on sex and gender in data collection and analysis, policy response and long-term recovery plans to avoid an increase in the existent worldwide gender inequalities in health (5). Numerous studies identified sex differences in COVID-19 morbidity and mortality worldwide (3). These differences frequently associate with differences in age, comorbidities and risk factors, such as smoking history and overweight $(6,7)$. In the Netherlands, a male:female mortality ratio of 1.25 has been reported $(8)$. 
Although these data align with global trends, no information about potential sex-specific risk factors in the Dutch population has been reported. Dutch healthcare relies heavily on a strong primary care system, and patients' transition to secondary and tertiary care is mostly limited to urgency, surgery, complexity or for conditions that cannot be managed in an outpatient setting. Direct access to hospital beyond urgency situations is discouraged. Overall, this could affect the disease severity of admitted patients in the Dutch healthcare system compared to others in Europe, where hospital care is accessed directly by patients without an active primary care gatekeeping. Given pre-pandemic international reports about potential sexand gender-related delays in diagnosis (9) and therapy $(10,11)$, admission and progression patterns of Dutch hospitalized patients should be explored in a sex-specific manner.

In addition to the overall challenge to the healthcare systems, the pandemic placed a specific strain on limited health care resources such as, among others, intensive care (12). In the Netherlands, patients are encouraged to make informed and active decisions about their health and the country has one of the most liberal euthanasia laws in Europe (13). During the first wave, physicians were encouraged to discuss ICU admission preferences with their patients, especially the ones where an ICU admission would not realistically improve the clinical outcome $(14,15)$. Based on these patient preferences and/or expected prognosis a decision is made whether or not the patient will be admitted to the ICU when indicated. Gender factors can influence these patient preferences. Previous research demonstrated that women were 1.3 times more likely than men to choose do-not-resuscitate (DNR) orders, another form of advanced care planning (ACP) (16). Other factors that could potentially influence the refusal of ICU care are age, comorbidities, ethnicity, and education. (17-19).

Given these findings, we designed the present study to explore sex differences in disease outcomes in a Dutch hospitalized COVID-19 patient population. Furthermore, we explored potential sex differences in non-ICU policy and factors contributing to this choice.

\section{Methods}

This is a multicenter observational cohort study. Patients have been consecutively included from six hospitals in the south-east of the Netherlands: one tertiary academic and five secondary non-academic hospitals (20). We included all patients above the age of 18, hospitalized for at least 24 hours with COVID19 and diagnosed by positive PCR test. We included patients during the first wave, lasting from March to May 2020; data collection took place until July $1^{\text {st }}$. The study population is a consecutive convenience sample, which was not originally recruited to specifically investigate sex differences. The enrolled numbers are representative of the sex differences in hospitalization during the first wave. The study was approved by the institutional review board (IRB) of the Radboud university medical center (Number 20202923 and 2020-6344). Oral consent was obtained from all patients or their family and documented in the electronic medical records.

Data collection and definitions 
Routine hospital data were collected upon admission. This included data on sex, age, body mass index (BMI) and comorbidities, such as solid organ malignancy, pulmonary disease, cardiovascular disease, diabetes mellitus, chronic kidney disease, and auto-immune disease. Symptoms at presentation were recorded as well as blood analysis results including, lactate dehydrogenase (LDH), C-reactive protein (CRP) and creatinine. Vital signs such as body temperature, heart rate, blood pressure and respiratory rate were recorded upon admission and regularly during hospital stay. A subset of patients was classified as "severely ill" upon admission. These individuals presented with clinical signs of pneumonia and one of the following: a respiratory rate of $<30$ per minute, sPO $2<90 \%$, or severe respiratory distress requiring ICU admission, need for a Venturi mask or non-rebreather mask (21).

We chose in-hospital mortality as the main measurable outcome. Outcomes measured in other studies such as admission to the ICU or mechanical ventilation were not applicable due to a significant percentage of patients with a non-ICU policy. Access to ICU and mechanical ventilation was, hence, not only dependent on medical indication, but also on personal preferences, age, and comorbidities. Patients with missing information about mortality were excluded from analysis.

Non-ICU policy was mostly recorded at hospital admission. This depended on a) active choice by the patient or b) negative clinical prognosis expressed by the caring physician, which was then discussed with the patient for concerted decision. Patients without a non-ICU policy could still make this decision during their permanence in the hospital. Patients classified as "unknown" for ICU preferences $(n=29)$ were recorded as "pro-ICU", assuming that if they had refused ICU admission this would have been noted.

\section{Analysis}

We performed descriptive statistics using chi-squared or t-tests for dichotomous and continuous variables, respectively. Firstly, to identify possible predictors of the primary outcome, in-hospital mortality, a literature search was performed. Potential predictors were chosen based on a meta-analysis including 148 different prognostic models and on a literature search for sex-specific predictors (22-27). To avoid overfitting the model, univariate analyses were used to test for association between the single predictors and the outcome, i.e. in-hospital mortality, for male and female patients separately. Predictors with an association with a $p$ value $<0.10$ for both men and women were included in the logistic regression. We included predictors as continuous variables. We excluded variables from the logistic regression when their incidence was rare, defined as an incidence lower than $5 \%$, because their added value to the prediction of the outcome was deemed too low. Variables were also excluded from the regression when the number of missing values was higher than $>10 \%$ of the total sample. For other variables missing values were imputed using the MICE package in $\mathrm{R}$.

The second part of this research focused on the patients with a non-ICU policy. We compared this group with the group that did not have a non-ICU policy, using sex-disaggregated data. Averages in the first and second half of the first wave were compared considering age and comorbidities. The first wave was split at the median admission date of this cohort, which was March 27, 2020 and coincides with the peak 
hospital admission date in the whole of the Netherlands (28). For the analysis chi-squared tests and ttests were used and a $p$ value of $<.05$ was deemed significant. Furthermore, we performed logistic regression analyses to assess the association between sex, age and comorbidities and ICU care refusal during the first and second half of the wave. All statistical analysis were performed using R studio software.

\section{Patient and public involvement}

There was no public or patient involvement in this research.

\section{Results}

\section{Demographics and comorbidities}

We included 1262 patients in this study, 36.3\% female and 63.7\% male patients. The median age was 69 years and 70 years, for female and male patients respectively (Table 1). The most common comorbidity was cardiovascular disease, which was significantly less frequent in female than in male patients $(53.7 \%$ vs $60.4 \%$, respectively). Other common comorbidities were pulmonary disease (including COPD) (24.7\% vs $23.5 \%)$, compromised immune function ( $22.5 \%$ vs $18.2 \%)$, and diabetes mellitus ( $21.6 \%$ vs $23.1 \%$, in female and male patients, respectively). 
Table 1

Characteristics of the study population

\begin{tabular}{|c|c|c|c|}
\hline IQR or $N(\%)$ & $\begin{array}{l}\text { Female patients } \\
\text { (458) }\end{array}$ & $\begin{array}{l}\text { Male patients } \\
(804)\end{array}$ & $\mathrm{p}$ value \\
\hline Age & $69(58-77)$ & $70(58-77)$ & .753 \\
\hline BMI* & $27.91(24.7-32.5)$ & $27.215(24.7-30.2)$ & $<0.001$ \\
\hline Restricted ICU admission policy & $155(33.8)$ & $246(30.6)$ & .234 \\
\hline \multicolumn{4}{|l|}{ Comorbidities } \\
\hline Hematological malignancy & $17(3.7)$ & $31(3.9)$ & .898 \\
\hline Solid organ malignancy & $69(15.1)$ & $121(15)$ & .994 \\
\hline Stem cell transplantation & $3(0.7)$ & $4(0.5)$ & .709 \\
\hline Solid organ transplantation & $5(1.1)$ & $9(1.1)$ & .964 \\
\hline Pulmonary disease (incl. COPD) & $113(24.7)$ & $189(23.5)$ & .641 \\
\hline $\begin{array}{l}\text { Cardiovascular disease (incl. } \\
\text { hypertension) }\end{array}$ & $246(53.7)$ & $486(60.4)$ & .020 \\
\hline Diabetes mellitus & $99(21.6)$ & $186(23.1)$ & .535 \\
\hline Chronic kidney disease & $52(11.4)$ & $83(10.3)$ & .569 \\
\hline Auto-immune disease (incl. IBD) ${ }^{\star \star}$ & $67(14.6)$ & $78(9.7)$ & .008 \\
\hline HIV/ AIDS & $1(0.2)$ & $0(0)$ & .363 \\
\hline 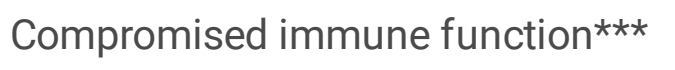 & $103(22.5)$ & $146(18.2)$ & .063 \\
\hline Liver disease & $10(2.2)$ & $20(2.5)$ & .733 \\
\hline Comorbidities total ( 1 or more) & $355(77.5)$ & $618(76.9)$ & .793 \\
\hline \multicolumn{4}{|l|}{ Admission } \\
\hline Symptom duration (days) & $7(5-10)$ & $7(5-11)$ & .033 \\
\hline Gastrointestinal symptoms & $289(63.1)$ & $430(53.5)$ & .001 \\
\hline Altered mental status & $16(3.5)$ & $35(4.3)$ & .394 \\
\hline Body temperature $\left({ }^{\circ} \mathrm{C}\right)$ & $37.8(37.1-38.6)$ & $37.9(37.2-38.7)$ & .651 \\
\hline
\end{tabular}

*Body mass index

**Inflammatory bowel disease

***Patients with hematologic malignancy, stem cell or organ transplantation, auto-immune disease, HIV/AIDS and/or use of immunosuppressive medication. 


\begin{tabular}{|c|c|c|c|}
\hline IQR or $\mathrm{N}(\%)$ & $\begin{array}{l}\text { Female patients } \\
\text { (458) }\end{array}$ & $\begin{array}{l}\text { Male patients } \\
(804)\end{array}$ & $\mathrm{p}$ value \\
\hline Systolic blood pressure (mmHg) & $133(118-148)$ & $134(123-148)$ & .195 \\
\hline Diastolic blood pressure (mmHg) & $75(66-85)$ & $78(69.25-86)$ & .030 \\
\hline Arterial blood pressure $(\mathrm{mmHg})$ & $95(86-104)$ & $97(89-105)$ & .037 \\
\hline Heart rate (BPM) & $90(81-104)$ & $89(78-103)$ & .255 \\
\hline Respiratory rate (bpm) & $22(18-26)$ & $23(19-28)$ & .009 \\
\hline Peripheral oxygen saturation (\%) & $94(91-96)$ & $94(92-96)$ & .261 \\
\hline SatO2 (\%) & $94(90-96)$ & $94(90-96)$ & .568 \\
\hline Ventilatory/oxygen supplementation & $153(33.4)$ & $311(38.7)$ & .049 \\
\hline LDH level (U/I) & $336(262-438)$ & $364.5(281-481)$ & .013 \\
\hline C-reactive protein level (mg/l) & $67.5(39-129)$ & $101(53-156)$ & $<.001$ \\
\hline Creatinine level (micromole/l) & $69(57-93)$ & $88(75-111)$ & $<.001$ \\
\hline \multicolumn{4}{|l|}{ Outcomes } \\
\hline Duration hospital stay (days) & $6(3-11)$ & $6(3-12)$ & .149 \\
\hline Illness duration till discharge (days) & $14(10-20)$ & $15(11-23)$ & .022 \\
\hline Ventilatory support during admission & $82(17.9)$ & $199(24.8)$ & .004 \\
\hline ICU admission & $69(15.1)$ & $175(21.8)$ & .001 \\
\hline Severely ill & $201(43.9)$ & $425(52.9)$ & .002 \\
\hline Readmitted to the hospital & $17(3.7)$ & $41(5.1)$ & .258 \\
\hline Died in hospital & $92(20.1)$ & $203(25.2)$ & .021 \\
\hline \multicolumn{4}{|l|}{${ }^{*}$ Body mass index } \\
\hline \multicolumn{4}{|l|}{ 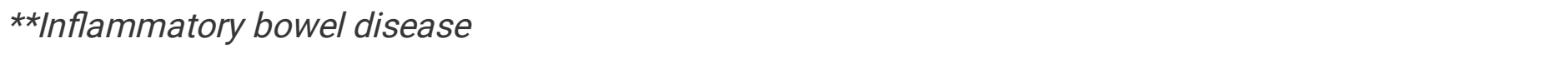 } \\
\hline $\begin{array}{l}* * * \text { Patients with hematologic malign } \\
\text { HIV/AIDS and/or use of immunosuph }\end{array}$ & $\begin{array}{l}n \text { cell or organ } t \\
\text { nedication. }\end{array}$ & tion, autc & ase, \\
\hline
\end{tabular}

On average female patients reported a 0.88 -day shorter symptom duration before admission to the hospital compared to men. Gastrointestinal symptoms such as vomiting and diarrhea were significantly more frequent in female patients (Table 1). Slight differences could be detected, such as lower diastolic blood pressure at admission, lower LDH level, C-reactive protein level and creatinine level in female patients compared to male ones (Table 1). Average duration of hospital stay was 6 days for both female and male patients. Male patients were significantly more likely to need ventilatory support $(24.8 \% \mathrm{vs}$ 
$17.9 \%)$, to be admitted to the ICU ( $21.8 \%$ vs $15.1 \%)$, and to die in hospital $(25.2 \%$ vs $20.1 \%)$ than female ones (Table 1).

\section{Predictors of in-hospital mortality}

Data on mortality were not available for 63 male (7.8\%) and 27 female patients (5.9\%). We excluded them from the analysis, which lead to a final sample of 1172 patients, 741 (63.2\%) male and $431(36.8 \%)$ female patients. We fitted logistic regression models based on previously reported results and univariate analysis. For both male and female patients higher age, higher LDH level, lower diastolic blood pressure, and lower peripheral oxygen saturation were associated with in hospital mortality. Only in female patients a shorter symptom duration and more comorbidities were associated with in-hospital mortality (Table 2).

Table 2

Logistic regression model with in-hospital mortality as dependent variable

\begin{tabular}{|c|c|c|c|c|}
\hline Women & multivariable OR & $95 \% \mathrm{Cl}$ & univariable OR & $95 \% \mathrm{Cl}$ \\
\hline Age & $1.073^{\star}$ & $1.045-1.101$ & $1.081^{\star}$ & $1.055-1.107$ \\
\hline Symptom duration & $0.916^{*}$ & $0.857-0.978$ & $0.910^{*}$ & $0.856-0.968$ \\
\hline LDH level & $1.003^{\star}$ & $1.001-1.005$ & $1.003^{\star}$ & $1.001-1.004$ \\
\hline C-reactive protein level & 1.001 & $0.997-1.005$ & 1.003 & $1.000-1.006$ \\
\hline Creatinine level & 1.001 & $0.997-1.004$ & $1.003^{\star}$ & $1.000-1.006$ \\
\hline Diastolic blood pressure & $0.979 *$ & $0.961-0.997$ & $0.969 *$ & $0.953-0.985$ \\
\hline Peripheral oxygen saturation & $0.948^{*}$ & $0.902-0.995$ & $0.936^{\star}$ & $0.898-0.974$ \\
\hline Comorbidities & $1.428^{*}$ & $1.125-1.813$ & $1.543^{*}$ & $1.267-1.879$ \\
\hline Men & multivariable OR & $95 \% \mathrm{Cl}$ & univariable OR & $95 \% \mathrm{Cl}$ \\
\hline Age & $1.105^{\star}$ & $1.081-1.130$ & $1.106^{\star}$ & $1.084-1.128$ \\
\hline Symptom duration & 0.980 & $0.944-1.017$ & $0.968^{*}$ & $0.937-1.000$ \\
\hline LDH level & $1.002^{*}$ & $1.001-1.004$ & $1.002^{\star}$ & $1.001-1.003$ \\
\hline C-reactive protein level & 1.001 & $0.998-1.003$ & $1.002^{\star}$ & $1.000-1.004$ \\
\hline Creatinine level & 1.002 & $0.999-1.003$ & $1.005^{\star}$ & $1.002-1.007$ \\
\hline Diastolic blood pressure & $0.985^{\star}$ & $0.970-0.999$ & $0.967^{\star}$ & $0.954-0.980$ \\
\hline Peripheral oxygen saturation & $0.957^{\star}$ & $0.917-0.998$ & $0.938^{*}$ & $0.905-0.972$ \\
\hline Comorbidities & 1.090 & 0.909-1.307 & $1.451^{*}$ & $1.259-1.673$ \\
\hline
\end{tabular}


155/458 (33.8\%) female and 246/804 (30.6\%) male patients admitted to the hospital had a non-ICU policy. Both female and male patients with non-ICU policy were significantly older than those without ICUrestrictions: 79 (IQR 73-84) vs 64 (IQR 54-70) years in female and 79 (IQR 74-83) vs 65 (IQR 55-72) years in male patients (see Table 3). People with non-ICU policy had significantly more comorbidities than those without. 
Table 3

Characteristics of patients separated in those that do or do not choose restricted ICU admission policy.

\section{Characteristics Women}

Characteristics Women

\begin{tabular}{|c|c|c|c|}
\hline & yes & no & \\
\hline & $155(33.8 \%)$ & $303(66.2 \%)$ & \\
\hline Age (IQR) & $79(73-84)$ & $64(54-70)$ & $<.001$ \\
\hline Comorbidities (total) & $2.01(1.10)$ & $1.23(1.09)$ & $<.001$ \\
\hline \multicolumn{4}{|l|}{ Comorbidities } \\
\hline Solid organ malignancy & $30(19.4 \%)$ & $39(12.9 \%)$ & .089 \\
\hline Pulmonary disease (incl. COPD) & $47(30.3 \%)$ & $66(22.8 \%)$ & .058 \\
\hline Cardiovascular disease (incl. hypertension) & $117(75.5 \%)$ & $129(42.6 \%)$ & $<.001$ \\
\hline Diabetes mellitus & $49(31.6 \%)$ & $50(16.5 \%)$ & $<.001$ \\
\hline Chronic kidney disease & $32(20.6 \%)$ & $20(6.6 \%)$ & $<.001$ \\
\hline Auto-immune disease (incl. IBD) & $21(13.5 \%)$ & $46(15.2 \%)$ & .742 \\
\hline \multirow[t]{3}{*}{ Characteristics Men } & \multicolumn{2}{|c|}{ Refusal of ICU care } & $\mathrm{p}$ value \\
\hline & yes & no & \\
\hline & $246(30.6 \%)$ & $558(69.4 \%)$ & \\
\hline Age (IQR) & $79(74-83)$ & $65(55-72)$ & $<.001$ \\
\hline Comorbidities (total) & $2.05(1.08)$ & $1.25(1.11)$ & $<.001$ \\
\hline \multicolumn{4}{|l|}{ Comorbidities } \\
\hline Solid organ malignancy & $61(24.8 \%)$ & $60(10.8 \%)$ & $<.001$ \\
\hline Pulmonary disease (incl. COPD) & $84(34.1 \%)$ & $105(18.8 \%)$ & $<.001$ \\
\hline Cardiovascular disease (incl. hypertension) & $199(80.9 \%)$ & $287(51.4 \%)$ & $<.001$ \\
\hline Diabetes mellitus & $63(25.6 \%)$ & $123(22.0 \%)$ & .310 \\
\hline Chronic kidney disease & $53(21.5 \%)$ & $30(5.4 \%)$ & $<.001$ \\
\hline Auto-immune disease (incl. IBD) & $32(13.0 \%)$ & $46(8.24 \%)$ & .048 \\
\hline
\end{tabular}

There was no statistically significant difference in the severity of illness between the groups with or without a restricted ICU admission policy. 132/246 (53.7\%) of male patients with a non-ICU policy were 
classified as severely ill versus $293 / 558(52.5 \%$, Table 3$)$ that were not. In the female patient group these numbers were $74 / 155$ (47.7\%) and $127 / 303(41.9 \%)$, respectively.

Changes in non-ICU policy over the course of the first wave

We could not identify any difference between male and female patients regarding ICU care choices in the first half of the first wave. However, when looking at the full duration of the first wave, the number of female patients with a non-ICU policy proportionally increased (from 29.3-39.6\%; $p=0.027$ ) while it decreased in male patients (from $33.3-27.1 \%, p=0.074$ ), leading to a significant difference in allocation to ICU care in the second half of the first wave (female $39.6 \%$ vs male patients $27.1 \%, p=0.002$, Figure 1 ). The total patient populations were comparable over the course of the first wave, the only identifiable difference was age in male patients. Male patients admitted in the second half were significantly younger, 67 years old (IQR 56-76) in the second half vs 72 years old (IQR 61-78) in the first half $(p<0.001)$, while the average age in female patients did not change. The mean change in age was related to a growing number of younger male patients being admitted; the age of male patients with non-ICU policy did not change (Figure 1).

We could not identify any significant difference in age, comorbidities, solid organ malignancy, pulmonary disease, cardiovascular disease, diabetes mellitus, chronic kidney disease, and autoimmune disease between the female and male patients with a restricted ICU admission policy in the first half versus the second half (see Figure 1).

Upon logistic regression, in the first half of the first wave, a non-ICU policy appeared to correlate with age as well as several comorbidities, however sex did not correlate with this choice. In the second half sex significantly correlated with presence of non-ICU policy (OR=1.964 for female patients, $95 \% \mathrm{Cl}=1.181$ 3.266 , Table 4), together with age and comorbidities. 
Table 4

Likelihood of no-ICU policy in the first and second half of the first COVID-19 wave in the Netherlands, adjusted by sex, age and comorbidities

\begin{tabular}{|c|c|c|c|c|}
\hline First half of the wave & $\begin{array}{l}\text { adjusted } \\
\text { OR }\end{array}$ & $95 \% \mathrm{Cl}$ & $\begin{array}{l}\text { unadjusted } \\
\text { OR }\end{array}$ & $95 \% \mathrm{Cl}$ \\
\hline Sex & 1.014 & $0.660-1.558$ & 0.813 & $\begin{array}{l}0.596- \\
1.159\end{array}$ \\
\hline Age & $1.188^{*}$ & $1.151-1.226$ & $1.198^{*}$ & $\begin{array}{l}1.163- \\
1.234\end{array}$ \\
\hline Hematological malignancy & $3.124^{\star}$ & $1.163-8.388$ & 1.452 & $\begin{array}{l}0.687- \\
3.068\end{array}$ \\
\hline Solid organ malignancy & 1.612 & $0.972-2.672$ & $2.189 *$ & $\begin{array}{l}1.461- \\
3.280\end{array}$ \\
\hline Solid organ transplantation & 0 & $x$ & 0 & $x$ \\
\hline Pulmonary disease (incl. COPD) & $1.661^{\star}$ & $1.041-2.647$ & $1.626^{\star}$ & $\begin{array}{l}1.137- \\
2.323\end{array}$ \\
\hline Chronic kidney disease & $2.523^{*}$ & $0.912-1.318$ & $3.809^{*}$ & $\begin{array}{l}2.358- \\
6.154\end{array}$ \\
\hline $\begin{array}{l}\text { Cardiovascular disease (incl. } \\
\text { hypertension) }\end{array}$ & 1.475 & $1.357-4.685$ & $3.576^{\star}$ & $\begin{array}{l}2.497- \\
5.122\end{array}$ \\
\hline Diabetes mellitus & 1.364 & $0.849-2.193$ & 1.374 & $\begin{array}{l}0.949- \\
1.989\end{array}$ \\
\hline Auto-immune disease (incl. IBD) & 1.075 & $0.582-1.985$ & 1.359 & $\begin{array}{l}0.837- \\
2.206\end{array}$ \\
\hline Liver disease & 0.945 & $0.284-3.141$ & 1.515 & $\begin{array}{l}0.569- \\
4.033\end{array}$ \\
\hline Second half of the wave & $\begin{array}{l}\text { adjusted } \\
\text { OR }\end{array}$ & $95 \% \mathrm{Cl}$ & $\begin{array}{l}\text { unadjusted } \\
\text { OR }\end{array}$ & $95 \% \mathrm{Cl}$ \\
\hline Sex & $1.964^{\star}$ & $1.184-3.257$ & $1.760^{\star}$ & $\begin{array}{l}1.219- \\
2.542\end{array}$ \\
\hline Age & $1.177^{\star}$ & $1.141-1.215$ & $1.185^{\star}$ & $\begin{array}{l}1.150- \\
1.222\end{array}$ \\
\hline Hematological malignancy & 1.195 & $0.249-5.732$ & 0.421 & $\begin{array}{l}0.120- \\
1.473\end{array}$ \\
\hline Solid organ malignancy & 1.260 & $0.660-2.406$ & $2.380 *$ & $\begin{array}{l}1.444- \\
3.922\end{array}$ \\
\hline Solid organ transplantation & 1.744 & $\begin{array}{l}0.145- \\
20.973\end{array}$ & 0.860 & $\begin{array}{l}0.165- \\
4.477\end{array}$ \\
\hline
\end{tabular}




\begin{tabular}{|c|c|c|c|c|}
\hline First half of the wave & $\begin{array}{l}\text { adjusted } \\
\text { OR }\end{array}$ & $95 \% \mathrm{Cl}$ & $\begin{array}{l}\text { unadjusted } \\
\text { OR }\end{array}$ & $95 \% \mathrm{Cl}$ \\
\hline Pulmonary disease (incl. COPD) & $2.312^{\star}$ & $1.330-4.018$ & $2.493^{\star}$ & $\begin{array}{l}1.661- \\
3.742\end{array}$ \\
\hline Chronic kidney disease & $2.450 *$ & $1.125-5.334$ & $5.347^{*}$ & $\begin{array}{l}2.945- \\
9.709\end{array}$ \\
\hline $\begin{array}{l}\text { Cardiovascular disease (incl. } \\
\text { hypertension) }\end{array}$ & 1.438 & $0.814-2.538$ & $4.587^{\star}$ & $\begin{array}{l}2.997- \\
7.020\end{array}$ \\
\hline Diabetes mellitus & 1.045 & $0.598-1.827$ & $1.779 *$ & $1.180-2.82$ \\
\hline Auto-immune disease (incl. IBD) & 1.107 & $0.545-2.251$ & 1.175 & $\begin{array}{l}0.684- \\
2.020\end{array}$ \\
\hline Liver disease & 0.441 & $0.070-2.791$ & 0.640 & $\begin{array}{l}0.174- \\
2.355\end{array}$ \\
\hline
\end{tabular}

\section{Discussion}

We investigated potential sex differences in a convenience sample of hospitalized patients during the first wave in the Netherlands. Given the specific cultural and health policy approach to intensive care (29), we specifically looked at patterns of ICU care preferences between female and male patients. In our study population, male patients were significantly more likely to need ventilatory support, be admitted to the ICU, and die in the hospital. Around a fifth of the patients died, which is consistent with other studies (30, 31). While we identified no sex differences in the prevalence of most risk factors, such as age, LDH level, and lower peripheral oxygen saturation, shorter symptom duration and an elevated number of comorbidities were associated with in-hospital mortality only in female patients.

Approximately a third of the patients had a non-ICU policy. People with a restricted policy were significantly older and had more comorbidities. There was a significant rise in non-ICU policies in female patients in the second half of the first wave compared to male ones, which could not be explained by age or comorbidities.

Our study confirmed the previously reported role of higher age, elevated LDH, lower diastolic blood pressure and lower peripheral oxygen saturation as predictors of in-hospital mortality in both male and female patients $(22,23,25,32-39)$. However, shorter symptom duration before hospitalization and more comorbidities were associated with in-hospital mortality in female patients only, contrary to most other studies that emphasized the role of comorbidities as risk predictors for COVID-19 mortality primarily in male ones $(34,40,41)$. In our study population male patients reported a higher prevalence of cardiovascular comorbidities, while female patients were affected more often by autoimmune conditions or taking immunosuppressive medications. Overall, the role of immunosuppression might have been more relevant than cardiovascular risk factors, highlighting the need for a potential stratification of risk factors for prediction of severe COVID-19. Furthermore, different co-morbidities might play a different role 
in female and male patients. Although SARS-CoV2's main target appears to be the vascular rather than the pulmonary system (42), the influence of the immune system is most essential in the development of the disease. This might especially apply to female patients. The role of sex differences in the susceptibility and progression of COVID-19 has been reviewed elsewhere (43). In general, female patients appear to experience an immune advantage due to genetics, hormonal influences or differences in innate immunity (44). If these fundamentally protective mechanisms are impaired, it might affect the disease susceptibility in female patients more substantially than in male ones leading to the potentially higher mortality we have identified in our cohort.

Another aspect leading to these differences might be the reported disease duration before admission. In our population, symptom duration before admission was significantly associated with in-hospital mortality only in female patients. Overall female patients reported a slightly shorter symptom duration before admission than men; a phenomenon that has been previously associated with in-hospital mortality $(45,46)$. The identified pattern could be due to two distinct factors: delay in health seeking by male patients or delayed symptom development in female patients. Health seeking delay has been extensively reported in male patients $(47,48)$ and could potentially skew the reported symptom duration. However, symptom development might also be different in female and male patients. Sex differences in symptomatology have been reported in many conditions. Especially in the field of cardiovascular health, the absence of symptoms in female patients (49) has notoriously led to delayed diagnosis and avoidable mortality (50). Given that COVID-19 is a vascular disease with predominantly pulmonary symptoms, a similar phenomenon could be at play. A recent meta-analysis has confirmed the lower prevalence of symptomatic COVID-19 in female patients (3) and their overall prognosis could thus be different than the one of male patients reporting the same severity or duration of symptoms upon admission to the hospital. This potential difference should be investigated in large cohorts, as it could be an essential sexspecific consideration for patient triage upon admission.

We then focused on ICU care preferences in female and male patients. A third of the patients refused ICU care. This is a significant percentage of the hospitalized and a phenomenon possibly unique to the Netherlands and few other countries with open societal discussions about end-of-life (EOL) choices (5153). The two main factors influencing this choice were older age and comorbidities (54). However, over the course of the first wave we saw a proportional increase in the female patients with a non-ICU policy and a decrease in male patients. The average age of male patients in the second half of the first wave decreased contributing to the lower proportional rate of non-ICU policies, however this age difference alone could not explain the identified sex differences. Given the lack of differences in co-morbidities, other factors might have been involved.

First, it appears as if a higher number of younger male patients were hospitalized in the second half of the first wave, as a potential consequence of more strict community-care triage of cases. Unfortunately, our current data does not allow the investigation of this aspects. Focusing on the female patients and the higher relative restricted non-ICU policy rates, we hypothesize the effect of multiple factors. Firstly, health literacy can impact choice of care. At the beginning of the pandemic there was a broad public debate 
about COVID-19, its disease course, and about what ICU care entails in the Netherlands. Given previous reports of higher health literacy in women (55), better understanding of ICU care and its consequences might have contributed to more reticence in accepting it. Second, gender differences have been reported in the attitude towards life-prolonging treatment options. For example, a previous study reported that more men chose to continue treatment if placed in a hypothetical coma with only a slight chance of recovery (56). Analogous reactions might have played out as primary care physicians discussed ICU options openly with their patients during the first wave (57). Third, gendered expectations might affect patients' choices. At the beginning of the pandemic, the possibility of ICU bed shortage was openly discussed in the media. Gender stereotypes include the characterization of "femininity" as being caring, nurturing and self-sacrificing (58). These stereotypes might be one of the underlying reasons for the higher rates of female living organ donors $(59,60)$. These expectations could lead to a potentially higher willingness in women to forgo an ICU treatment to benefit younger patients. Fourth, gender-specific communication differences between physicians and patients could impact choices. Research on do not resuscitate (DNR) orders showed that overall female physicians were more inclined to have this discussion with their patients and female physicians were 1.5 times more likely to write DNR orders for their female than for their male patients (16). Patient-provider dyads might, thus, have had a potential influence on ICU care choices. Last, gender norms and relations might impact EOL preferences. Active choice to forgo invasive treatment with long-term consequences might be an informed choice rather than any expression of discrimination by the health care provider or system. Little is known about the underlying reasons for gender differences in EOL preferences, but current literature suggests more willingness to spontaneously discuss death by women with their healthcare providers (61) and more openness to discuss the emotional aspects of dying (62).

The current study offers a realistic perspective of hospitalization patterns in the Netherlands during the first wave, but some limitations should be acknowledged. In approximately $7 \%$ of the cases, we did not have information about mortality, mainly due to transfer of patients. However, the overall patterns recapitulate the situation in the country at the time, so this should not represent a meaningful source of bias. Second, the high non-ICU policy rates in the included population offered an ideal setting to study these patterns, but limited the ability to predict the potential outcomes of patients that might have experienced a positive outcome if given ICU care. Hence, the calculated risk factor associations might be influenced by a subgroup of patients that willingly chose to forgo ICU care. Last, we investigated the impact of sex, age and comorbidities on ICU choices but did not include other potentially influential factors, such as e.g. ethnicity, living situation/marital status and education (17-19). These data were not available in the current database and should be investigated in future research.

\section{Perspectives and Significance}

Overall, we confirmed the previously reported higher incidence of severe disease and mortality in male compared to female patients with COVID-19. However, we also identified sex differences in the impact of symptom duration before admission and markers of immune disfunction on prognosis. Given the potential prognostic value of the speed of symptom development and immune dysfunction in female 
patients, this should be specifically investigated to possibly inform sex-specific triage protocols for COVID-19. Last, sex and gender differences in ICU care preferences should be further investigated. Our data highlights some unexplained differences in ICU care policy, which cannot be solely explained on clinical grounds. Further studies are needed to evaluate the potential role of gender in care choices and active priority setting at the end-of-life (EOL). Furthermore, patient-provider communication at EOL in the context of health care urgency and restricted availability such as the COVID-19 first wave should be further explored.

\section{Declarations}

Ethics approval and consent to participate: The study was approved by the institutional review board (IRB) of the Radboud university medical center (Number 2020-2923 and 2020-6344).

Consent for publication: not applicable

Availability of data and material: The data is available upon request

Competing interests: The authors declare that they have no competing interests.

Funding: No specific funding was available for this study.

Authors' contributions: SOP designed the study, JH, AD, NJ, MB, RJH, MvA, AK, KV and JvdM collected data, AF, SOP and JvdM analyzed the data, AF and SOP drafted the manuscript, JH, AD, NJ, MB, RJH, MvA, AK, KV and JvdM reviewed the manuscript for important intellectual content.

Acknowledgements: We would like to thank all participants and their relatives who supported us in the data collection for this study in very difficult times.

\section{References}

1. Control ECfDPa. COVID-19 situation update worldwide, as of week 5220202020 [Available from: https://www.ecdc.europa.eu/en/geographical-distribution-2019-ncov-cases.

2. RIVM. Actuele informatie over het coronavirus SARS-CoV-2 [Available from: https://www.rivm.nl/coronavirus-covid-19/actueel.

3. Abate BB, Kassie AM, Kassaw MW, Aragie TG, Masresha SA. Sex difference in coronavirus disease (COVID-19): a systematic review and meta-analysis. BMJ Open. 2020;10(10):e040129.

4. Wenham C, Smith J, Morgan R. COVID-19: the gendered impacts of the outbreak. The Lancet. 2020;395.

5. Wenham C, Smith J, Morgan R. COVID-19: the gendered impacts of the outbreak. The Lancet. 2020;395(10227):846-8.

6. Lai CC, Shih TP, Ko WC, Tang HJ, Hsueh PR. Severe acute respiratory syndrome coronavirus 2 (SARSCoV-2) and coronavirus disease-2019 (COVID-19): The epidemic and the challenges. Int J Antimicrob 
Agents. 2020;55(3):105924.

7. Fehr AR, Channappanavar R, Perlman S. Middle East Respiratory Syndrome: Emergence of a Pathogenic Human Coronavirus. Annu Rev Med. 2017;68(1):387-99.

8. Annabel N, Anne T, Scott M, Wim van der H. Rianne van G-L, Mirjam K. European Journal of Epidemiology. 2021.

9. Westergaard D, Moseley P, Sørup FKH, Baldi P, Brunak S. Population-wide analysis of differences in disease progression patterns in men and women. Nat Commun. 2019;10(1):666.

10. Bugiardini R, Ricci B, Cenko E, Vasiljevic Z, Kedev S, Davidovic G, et al. Delayed Care and Mortality Among Women and Men With Myocardial Infarction. J Am Heart Assoc. 2017;6(8).

11. Aziz A, Madersbacher S, Otto W, Mayr R, Comploj E, Pycha A, et al. Comparative Analysis of GenderRelated Differences in Symptoms and Referral Patterns prior to Initial Diagnosis of Urothelial Carcinoma of the Bladder: A Prospective Cohort Study. Urol Int. 2015;94(1):37-44.

12. LNAZ. Opschalingsplan COVID-19. Landelijk Netwerk Acute Zorg; 2020.

13. Gesprekshulp behandelgrenzen. In: PATIENT+, editor. Den Haag2020.

14. Fuchs L, Chronaki CE, Park S, Novack V, Baumfeld Y, Scott D, et al. ICU admission characteristics and mortality rates among elderly and very elderly patients. Intensive Care Med. 2012;38(10):1654-61.

15. Desai SV, Law TJ, Needham DM. Long-term complications of critical care. Crit Care Med. 2011;39(2):371-9.

16. Crosby MA, Cheng L, DeJesus AY, Travis EL, Rodriguez MA. Provider and Patient Gender Influence on Timing of Do-Not-Resuscitate Orders in Hospitalized Patients with Cancer. J Palliat Med. 2016;19(7):728-33.

17. Boerner K, Carr D, Moorman S. Family relationships and advance care planning: do supportive and critical relations encourage or hinder planning? J Gerontol B Psychol Sci Soc Sci. 2013;68(2):24656.

18. Resnick L, Cowart ME, Kubrin A. Perceptions of do-not-resuscitate orders. Soc Work Health Care. 1998;26(4):1-21.

19. Rao JK, Anderson LA, Lin FC, Laux JP. Completion of advance directives among U.S. consumers. Am J Prev Med. 2014;46(1):65-70.

20. Pouw N, van de Maat J, Veerman K, ten Oever J, Janssen N, Abbink E, et al. Clinical characteristics and outcomes of 952 hospitalized COVID-19 patients in The Netherlands: A retrospective cohort study. PLoS ONE. 2021;16(3):e0248713.

21. Organization WH. Clinical management of COVID-19 Webstie2020 [updated 27 May 2020. Available from: https://www.who.int/publications/i/item/clinical-management-of-covid-19.

22. Hu J, Zhou J, Dong F, Tan J, Wang S, Li Z, et al. Combination of serum lactate dehydrogenase and sex is predictive of severe disease in patients with COVID-19. Med (Baltim). 2020;99(42):e22774.

23. Wynants L, Van Calster B, Collins GS, Riley RD, Heinze G, Schuit E, et al. Prediction models for diagnosis and prognosis of covid-19: systematic review and critical appraisal. BMJ. 
2020;369:m1328.

24. Bhopal SS, Bhopal R. Sex differential in COVID-19 mortality varies markedly by age. The Lancet. 2020;396(10250):532-3.

25. Henry BM, Aggarwal G, Wong J, Benoit S, Vikse J, Plebani M, et al. Lactate dehydrogenase levels predict coronavirus disease 2019 (COVID-19) severity and mortality: A pooled analysis. Am J Emerg Med. 2020;38(9):1722-6.

26. Luo X, Zhou W, Yan X, Guo T, Wang B, Xia H, et al. Prognostic Value of C-Reactive Protein in Patients With Coronavirus 2019. Clin Infect Dis. 2020;71(16):2174-9.

27. Haitao T, Vermunt JV, Abeykoon J, Ghamrawi R, Gunaratne M, Jayachandran M, et al. COVID-19 and Sex Differences: Mechanisms and Biomarkers. Mayo Clin Proc. 2020;95(10):2189-203.

28. RIVM. Ontwikkeling. COVID-19 in grafieken: Rijksunstituut voor Volksgezondheid en Milieu; 2021 [updated 04-05-2021. Available from: https://www.rivm.nl/coronavirus-covid-19/grafieken.

29. Verweij M, van de Vathorst S, Schermer M, Willems D, de Vries M. Ethical Advice for an Intensive Care Triage Protocol in the COVID-19 Pandemic: Lessons Learned from The Netherlands. Public Health Ethics. 2020;13(2):157-65.

30. Wiersinga WJ, Rhodes A, Cheng AC, Peacock SJ, Prescott HC. Pathophysiology, Transmission, Diagnosis, and Treatment of Coronavirus Disease 2019 (COVID-19): A Review. JAMA. 2020;324(8):782-93.

31. Goel S, Jain T, Hooda A, Malhotra R, Johal G, Masoomi R, et al. Clinical Characteristics and InHospital Mortality for COVID-19 Across The Globe. Cardiol Therapy. 2020;9(2):553-9.

32. Parohan M, Yaghoubi S, Seraji A, Javanbakht MH, Sarraf P, Djalali M. Risk factors for mortality in patients with Coronavirus disease 2019 (COVID-19) infection: a systematic review and meta-analysis of observational studies. Aging Male. 2020;23(5):1416-24.

33. Lu L, Zhong W, Bian Z, Li Z, Zhang K, Liang B, et al. A comparison of mortality-related risk factors of COVID-19, SARS, and MERS: A systematic review and meta-analysis. J Infect. 2020;81(4):e18-25.

34. Li G, Liu Y, Jing X, Wang Y, Miao M, Tao L, et al. Mortality risk of COVID-19 in elderly males with comorbidities: a multi-country study. Aging. 2020;13(1):27-60.

35. Erez A, Shental O, Tchebiner JZ, Laufer-Perl M, Wasserman A, Sella T, et al. Diagnostic and prognostic value of very high serum lactate dehydrogenase in admitted medical patients. Isr Med Assoc J. 2014;16(7):439-43.

36. Xie J, Covassin N, Fan Z, Singh P, Gao W, Li G, et al. Association Between Hypoxemia and Mortality in Patients With COVID-19. Mayo Clin Proc. 2020;95(6):1138-47.

37. Mejía F, Medina C, Cornejo E, Morello E, Vásquez S, Alave J, et al. Oxygen saturation as a predictor of mortality in hospitalized adult patients with COVID-19 in a public hospital in Lima, Peru. PLoS ONE. 2021;15(12):e0244171.

38. Mikami T, Miyashita H, Yamada T, Harrington M, Steinberg D, Dunn A, et al. Risk Factors for Mortality in Patients with COVID-19 in New York City. J Gen Intern Med. 2021;36(1):17-26. 
39. Moledina SM, Maini AA, Gargan A, Harland W, Jenney H, Phillips G, et al. Clinical Characteristics and Predictors of Mortality in Patients with COVID-19 Infection Outside Intensive Care. Int J Gen Med. 2020;13:1157-65.

40. Biswas M, Rahaman S, Biswas TK, Haque Z, Ibrahim B. Association of Sex, Age, and Comorbidities with Mortality in COVID-19 Patients: A Systematic Review and Meta-Analysis. Intervirology. 2021;64(1):36-47.

41. Sanyaolu A, Okorie C, Marinkovic A, Patidar R, Younis K, Desai P, et al. Comorbidity and its Impact on Patients with COVID-19. SN Compr Clin Med. 2020:1-8.

42. Teuwen LA, Geldhof V, Pasut A, Carmeliet P. COVID-19: the vasculature unleashed. Nat Rev Immunol. 2020;20(7):389-91.

43. Scully EP, Haverfield J, Ursin RL, Tannenbaum C, Klein SL. Considering how biological sex impacts immune responses and COVID-19 outcomes. Nat Rev Immunol. 2020;20(7):442-7.

44. Takahashi T, Iwasaki A. Sex differences in immune responses. Science. 2021;371(6527):347-8.

45. Alaa A, Qian Z, Rashbass J, Benger J, van der Schaar M. Retrospective cohort study of admission timing and mortality following COVID-19 infection in England. BMJ Open. 2020;10(11):e042712.

46. Azoulay E, Fartoukh M, Darmon M, Géri G, Voiriot G, Dupont T, et al. Increased mortality in patients with severe SARS-CoV-2 infection admitted within seven days of disease onset. Intensive Care Med. 2020;46(9):1714-22.

47. Höhn A, Gampe J, Lindahl-Jacobsen R, Christensen K, Oksuyzan A. Do men avoid seeking medical advice? A register-based analysis of gender-specific changes in primary healthcare use after first hospitalisation at ages 60+ in Denmark. J Epidemiol Commun Health. 2020;74(7):573.

48. Hale S, Grogan S, Willott S. Male GPs' views on men seeking medical help: a qualitative study. Br J Health Psychol. 2010;15(Pt 4):697-713.

49. Canto JG, Rogers WJ, Goldberg RJ, Peterson ED, Wenger NK, Vaccarino V, et al. Association of Age and Sex With Myocardial Infarction Symptom Presentation and In-Hospital Mortality. JAMA. 2012;307(8):813-22.

50. Vaccarino V, Parsons L, Every NR, Barron HV, Krumholz HM. Sex-based differences in early mortality after myocardial infarction. National Registry of Myocardial Infarction 2 Participants. N Engl J Med. 1999;341(4):217-25.

51. Robert Chesal DO. Waarom Nederland vergeleken met ander landen weinig IC-bedden heeft. NOS. 2020.

52. Heerde Jv. Oudere met corona komt veel minder gauw op de intensive care. Trouw. 2020.

53. Fogteloo M. Wie krijgt dat schaarse ic-bed? De Groene Amsterdammer. 2020 08-04-2020.

54. Wenger NS, Pearson ML, Desmond KA, Harrison ER, Rubenstein LV, Rogers WH, et al. Epidemiology of do-not-resuscitate orders. Disparity by age, diagnosis, gender, race, and functional impairment. Arch Intern Med. 1995;155(19):2056-62. 
55. Lee HY, Lee J, Kim NK. Gender Differences in Health Literacy Among Korean Adults: Do Women Have a Higher Level of Health Literacy Than Men? Am J Mens Health. 2015;9(5):370-9.

56. Bookwala J, Coppola KM, Fagerlin A, Ditto PH, Danks JH, Smucker WD. Gender differences in older adults' preferences for life-sustaining medical treatments and end-of-life values. Death Stud. 2001;25(2):127-49.

57. Specialists FoM. Triage thuisbehandeling versus verwijzen naar het ziekenhuis bij oudere patiënt met (verdenking op) COVID-19 [updated 24 August 2020. Available from: https://www.demedischspecialist.nl/sites/default/files/Leidraad\% 20triage\%20thuisbehandeling\%20versus\%20verwijzen\%20oudere\%20patiënt\% 20met\%20verdenking\%20COVID-19.pdf.

58. Bem SL. The measurement of psychological androgyny. J Consult Clin Psychol. 1974;42(2):155-62.

59. Bloembergen WE, Port FK, Mauger EA, Briggs JP, Leichtman AB. Gender discrepancies in living related renal transplant donors and recipients. J Am Soc Nephrol. 1996;7(8):1139-44.

60. Esplen E, Studies BloD. Gender and care: overview report. Institute of Development Studies Brighton; 2009.

61. Skulason B, Hauksdottir A, Ahcic K, Helgason AR. Death talk: gender differences in talking about one's own impending death. BMC Palliat Care. 2014;13(1):8.

62. Seifart C, Riera Knorrenschild J, Hofmann M, Nestoriuc Y, Rief W, von Blanckenburg P. Let us talk about death: gender effects in cancer patients' preferences for end-of-life discussions. Support Care Cancer. 2020;28(10):4667-75.

\section{Figures}




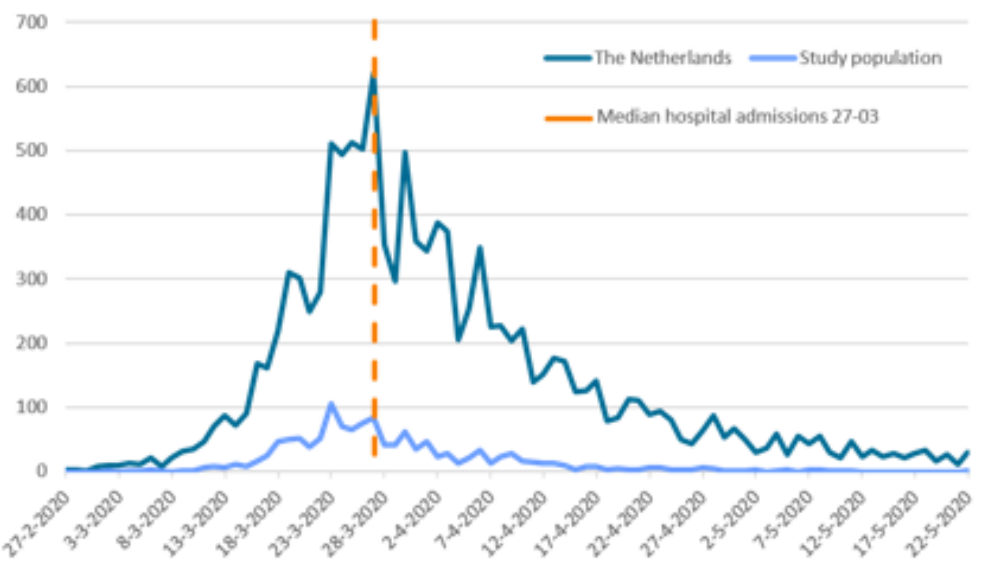

\begin{tabular}{|c|c|c|c|}
\hline & First half 2-26 March & Second half 27 March - 22 Mar & pvalue \\
\hline \multicolumn{4}{|l|}{ Women that have a restricted ICU policy } \\
\hline $\mathrm{N}$ & $75 / 256(29.3 \%)$ & $80 / 202(39.6 \%)$ & .027 \\
\hline Age (IQR) & $78(74-83)$ & $80(73-85)$ & .971 \\
\hline Comorbidities (mean (SD)) & $2.05(1.02)$ & $1.95(1.18)$ & .563 \\
\hline Solid organ malignancy & $19(25.3 \%)$ & $11(13.8 \%)$ & .105 \\
\hline Pulmonary disease (incl. COPD) & $21(28 \%)$ & $26(32.5 \%)$ & .664 \\
\hline Cardiovascular disease (incl. hypertension) & $56(74.6 \%)$ & $61(76.3 \%)$ & .966 \\
\hline Diabetes mellitus & $25(33.3 \%)$ & $24(30 \%)$ & .785 \\
\hline Chronic kidney disease & $12(16 \%)$ & $20(25 \%)$ & .236 \\
\hline Auto-immune disease (incl. IBD) & $12(16 \%)$ & $9(11.3 \%)$ & .530 \\
\hline \multicolumn{4}{|l|}{ Men that have a restricted ICU policy } \\
\hline $\mathrm{N}$ & $151 / 454(33.3 \%)$ & $95 / 350(27.1 \%)$ & .074 \\
\hline Age (IQR) & $79(74-83)$ & $79(73-83)$ & .364 \\
\hline Comorbidities (mean (SD)) & $1.99(1.06)$ & $2.15(1.12)$ & .282 \\
\hline Solid organ malignancy & $36(23.8 \%)$ & $25(26.3 \%)$ & .775 \\
\hline Pulmonary disease (incl. COPD) & $48(31.8 \%)$ & $36(37.9 \%)$ & .398 \\
\hline Cardiovascular disease (incl. hypertension) & $119(78.8 \%)$ & $80(84.2 \%)$ & .377 \\
\hline Diabetes mellitus & $34(22.5 \%)$ & $29(30.5 \%)$ & .211 \\
\hline Chronic kidney disease & $36(23.8 \%)$ & $17(17.9 \%)$ & .345 \\
\hline Auto-immune disease (incl. IBD) & $18(11.9 \%)$ & $14(14.7 \%)$ & .657 \\
\hline
\end{tabular}

\section{Figure 1}

Clinical comparison of the groups with a no-ICU policy in the first and the second half of the first wave. 